\title{
Food Insecurity and the Risk of Obesity, Depression, and Self-Rated Health in Women
}

\author{
Sydney K. Willis, ${ }^{1, *}$ Sara E. Simonsen, ${ }^{2}$ Rachael B. Hemmert, ${ }^{2}$ Jami Baayd, ${ }^{2}$ Kathleen B. Digre, ${ }^{3}$ and Cathleen D. Zick ${ }^{4}$
}

\begin{abstract}
Background/Introduction/Objective: Recent studies have shown that food insecurity is associated with obesity, depression, and other adverse health outcomes although little research has been focused on these relationships in underrepresented cultural and social groups. In this study we elucidate the relationship between food insecurity, community factors, dietary patterns, race/ethnicity and health among underrepresented women.

Materials and Methods: The data for this investigation come from a cross-sectional survey of women drawn from five urban Utah communities of color, including African immigrants/refugees, African Americans, Hispanics, American Indians/Alaska Natives, and Pacific Islanders, and women from four rural Utah counties. Multivariate logistic regression was used to assess the relationship between food insecurity and obesity risk, self-reported depression, and self-assessed health.

Results: Urban women of color were more likely to report food insecurity than rural non-Hispanic white women. Obesity and depression scores were positively associated with food insecurity.

Conclusions: Utah women of color had higher levels of food insecurity than reported in state or national data, highlight an important disparity. Nutritional education initiatives, evaluating food assistance programs, and screenings in clinical settings targeting specific racial/ethnic groups may help address the disparities observed in this study.
\end{abstract}

Keywords: depression; food insecurity; obesity; self-rated health

\section{Introduction}

Food insecurity is defined as "limited or uncertain availability of nutritionally adequate and safe foods or limited or uncertain ability to acquire acceptable foods in socially acceptable ways." ${ }^{\text {" Nationwide, food }}$ insecurity affected between $10 \%$ and $12 \%$ of households from 1995 to 2007 and increased to roughly $14 \%$ during the 2008-2009 recession. Levels have since returned to around $13 \%{ }^{2}$

Rates are higher for economically or socially disadvantaged populations. Households with minor children, ${ }^{3}$ older individuals, ${ }^{3}$ individuals living in rural areas, ${ }^{2}$ and women ${ }^{4}$ all experience higher rates of food insecurity, with women of color and rural women facing increased risks due to the intersection of these factors. ${ }^{2,5}$ Recent studies have shown that food insecurity is associated with obesity, ${ }^{6}$ depression, ${ }^{7-9}$ type 2 diabetes, ${ }^{10,11}$ and other adverse health outcomes. $^{12}$

Although many studies have found an association between obesity and food insecurity, especially in women, ${ }^{6}$ the current literature lacks a detailed exploration of the relationship between food insecurity and health in underrepresented cultural and social groups,

${ }^{1}$ Department of Epidemiology, Boston University School of Public Health, Boston, Massachusetts, USA.

${ }^{2}$ College of Nursing, University of Utah, Salt Lake City, Utah, USA.

Departments of ${ }^{3}$ Neurology and Ophthalmology and ${ }^{4}$ Family and Consumer Studies, University of Utah, Salt Lake City, Utah, USA.

*Address correspondence to: Sydney K. Willis, MSPH, Department of Epidemiology, Boston University School of Public Health, 715 Albany Street, Boston, MA 02118, USA, E-mail: siwillis@bu.edu

(C) Sydney K. Willis et al. 2020; Published by Mary Ann Liebert, Inc. This Open Access article is distributed under the terms of the Creative Commons License (http://creativecommons.org/licenses/by/4.0), which permits unrestricted use, distribution, and reproduction in any medium, provided the original work is properly cited. 
particularly among those with limited representation in prior research such as Pacific Islanders and African refugee and immigrant populations. ${ }^{13,14}$

The goal of this study was to elucidate the relationship between food insecurity, community factors, dietary patterns, race/ethnicity, and health among women in both rural and urban communities. We sought to examine (1) individual, community, and dietary factors associated with the presence of selfreported household food insecurity among women from five urban communities of color and rural nonHispanic white women; (2) the association between obesity, depression, and self-perceived health and food insecurity in these groups.

\section{Materials and Methods \\ Study population}

This study was a cross-sectional analysis using data drawn from the Coalition for a Healthier Community for Utah Women and Girls (UWAG) study. UWAG was conducted through a partnership with Community Faces of Utah (CFU), an organization representing five urban communities of color, four rural communities, the University of Utah, the Utah State University Extension Program, and the Utah Department of Health. The larger study focused on assessing the effectiveness of a 12-month wellness coaching intervention on women's physical activity levels and dietary habits. ${ }^{15}$

Members of each respective community were trained as wellness coaches by the UWAG team to serve as community health workers focusing on preventive health. Wellness coaches recruited study participants at community events, including health fairs, churches, and cultural events, and through snowball recruitment techniques, where interested friends or family members of study participants were enrolled.

Once recruited, participants completed a baseline interview and wellness coaches collected anthropometric measures. After the collection of baseline measures, participants were randomized into a low- or highintensity year-long intervention designed to promote healthy eating and physical activity. Detailed information about UWAG study methods and the costeffectiveness of the intervention have been previously published. ${ }^{15-17}$ All study procedures were approved by the University of Utah Institutional Review Board and the Phoenix Area Indian Health Service Institutional Review Board. Verbal informed consent was obtained from all subjects/patients.
All data used in the current analysis were collected at baseline, before randomization. Rural, African American, Pacific Islander, and American Indian/Alaska Native (AI/AN) respondents completed an English survey. Hispanic respondents had the option of completing either an English or Spanish survey. African immigrant/refugee respondents from Burundi and Rwanda completed the survey in Kirundi.

Urban recruitment took place in Salt Lake County, a densely populated county in which one out of five residents speak English as a second language, and one out of eight residents are born outside of the United States. ${ }^{18}$ White non-Hispanic rural participants were recruited in San Juan, Beaver, Emery, and Duchesne counties. The population density of these counties ranges from 1.9 to 5.7 people per square mile in comparison to Salt Lake County, which has 33.6 people per square mile. ${ }^{19}$

\section{Measures}

In-person, computer-assisted interviews were used to collect data on food insecurity, depression, and selfrated health. Food insecurity was assessed with the following question, which was adapted from a Behavioral Risk Factor Surveillance System (BRFSS) question that incorporated feedback from community partners: "How many days, in the past 30 days have you been concerned about having enough food for you or your family?" Response options included: "all of the days," "most of the days," "some of the days," or "none of the days." Food insecurity was determined to be present if a respondent answered "all of the days," "most of the days," or "some of the days" and absent if a respondent answered "none of the days."20

All participants were screened for depression by using the Public Health Questionnaire-2 (PHQ-2) at baseline. Those scoring 3 or higher on the PHQ-2 were considered to have a positive depression screen. ${ }^{21}$ Data on self-perceived health came from a validated BRFSS question asked on the baseline survey: "How would you rate your health?" Response options included: "excellent," "very good," "good," "fair," or "poor." Participants were categorized into either "poor" or "fair" self-rated health versus "excellent," "very good," or "good" self-rated health.

Anthropometric data included height, weight, waist circumference, hip circumference, and blood pressure. Wellness coaches were trained to take anthropometric measurements by using standardized approaches such 
as zeroing the scale before each measurement and removing the participants' shoes. Body mass index (BMI) was calculated based on body weight $(\mathrm{kg})$ divided by height $(\mathrm{cm})$ squared. Obesity was defined as BMI $\geq 32$ for Pacific Islanders and $\mathrm{BMI} \geq 30$ for all other groups. ${ }^{22-24}$

In-person, computer-assisted interviews were also used to collect data on demographics, health status, health care access, health literacy, diet and exercise behaviors, attitudes, quality of life, social support, and environmental factors.

Community membership included self-identified membership as AI/AN, Hispanic, Pacific Islander, African immigrant or refugee, African American, or rural non-Hispanic white. Income was categorized based on the percent of the federal poverty level (FPL) $(<100,101-130,131-185,>185 \%$ FPL, and not reported). Age (18-29, 30-39, 40-49, and $\geq 50$ years) and education ( $<$ high school, high school graduate, some college, and $\geq$ college graduate) were self-reported by participants during the baseline interview.

Information on food consumption was collected by asking weekly intake of fast food, soda, orange vegetables, green vegetables, beans, "other" vegetables (including tomato, corn, eggplant, peas, lettuce, cabbage, and white potatoes), water, juice, and fruit intake by using questions from the BRFSS survey and classified into consumption of $\geq 5$ fruit and vegetables per day (yes vs. no). ${ }^{21}$

Information on physical activity was ascertained by asking, "In an average week, how much time do you spend being physically active or doing exercise?." 25 The threshold for receipt of adequate physical activity was based on the CDC's definition of meeting guidelines: 2.5 hours or more per week of moderate to vigorous physical activity. ${ }^{25}$

Residential addresses of study participants were geocoded by using a Geographic Information System (GIS). Geocoded addresses were overlaid onto census tract level data provided by the Food Access Research Atlas (FARA). ${ }^{26}$ FARA, developed by the Economic Research Service of the United States Department of Agriculture, is a collection of spatial food insecurity variables including the location of low-income census tracts, food deserts, and census tracts that have limited access to food distributors such as grocery stores.

FARA defines low-income census tracts as any tract with one or more of the following characteristics: "poverty rate is 20 percent or greater; the tract's median family income is less than or equal to 80 percent of the State-wide median family income; or the tract is in a metropolitan area and has a median family income less than or equal to 80 percent of the metropolitan area's median family income." 27 Limited access census tracts are defined by distance to the nearest grocery store or supermarket. Distances greater than or equal to $1 / 2$ mile in urban areas and 10 miles for rural tracts are considered low access. Food deserts are census tracts that are both low income and low access.

We used analysis of variance and chi-square tests to assess differences in dietary factors between individuals with self-reported food insecurity within the past 30 days (some and most or all days) and individuals without food insecurity in the past 30 days. We used multivariable logistic regression to obtain the odds of having any food insecurity compared with having no food insecurity and 95\% confidence intervals (95\% $\mathrm{CI})$. For the multivariable logistic regression, we combined levels of any reported food insecurity in the past 30 days (compared with no reported food insecurity) due to small counts for those who reported food insecurity for most or all of the past 30 days.

Two multivariate models were estimated: Model A with mutual adjustment for other health outcomes (BMI, positive depression score, self-rated health); Model B with adjustment for covariates in model A as well as demographic and community factors including community group, minor children in the home, percent of FPL, residing in a food desert, age, education, meeting physical activity guidelines, and consumption of five or more fruits/vegetables per day. As we compared three health outcomes, we applied the Bonferroni correction to p-values for the main health outcomes, using a $p$-value of 0.017 as our alpha level. All covariates and interactions included in the multivariate regression were determined a priori and were assessed for collinearity. No covariates included in the models were determined to be collinear.

Data were analyzed by using StataSE14 (College Station, TX), SAS version 9.4 (SAS Institute, Cary, NC), qGIS 2.18.9, and ArcGIS 10.x (Redlands, CA).

\section{Results}

A total of 516 women enrolled in the study and completed the baseline interview. The racial/ethnic makeup of participants was $15 \%$ African Immigrant/ Refugee, 19\% African American, 26\% Hispanic, 16\% Pacific Islander, $14 \% \mathrm{AI} / \mathrm{AN}$, and $10 \%$ rural nonHispanic white. The average age of the participants was 42 years old, and the majority of participants had children younger than the age of 18 living at home. 
More than two-thirds of the participants had a household income less than 185\% FPL adjusted for household size (Table 1) with African, Hispanic, and $\mathrm{AI} / \mathrm{ANs}$ having the largest proportion of respondents with incomes $<185 \%$ of the FPL (data not shown). The modal educational level was "some college." Slightly more than one-fifth of participants lived in a food desert as defined as census tracts that are both low income and low access.

The health indicators in Table 1 suggest that study participants experience a number of health challenges, as $44 \%$ rated their overall health as either fair or poor and $20 \%$ had a positive PHQ-2 depression screen. Slightly more than $83 \%$ were overweight or obese.

Table 1. Demographic Characteristics of 516 Utah Women and Girl Study Participants at Baseline

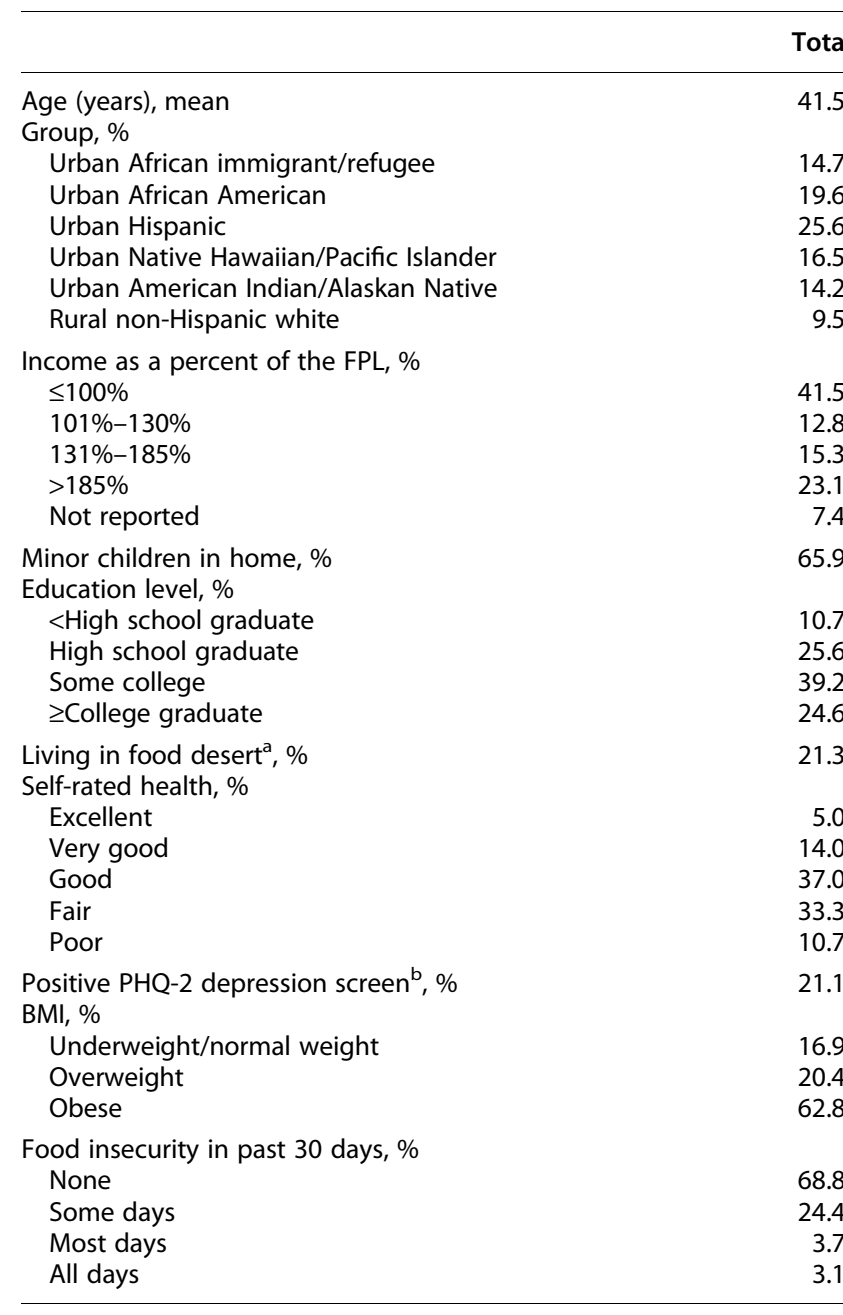

${ }^{\text {a }}$ Food Desert defined as low income and low access tract measured at 1 mile for urban areas and 10 miles for rural areas.

${ }^{\mathrm{b}}$ Positive screening defined as PHQ-2 score $\geq 3$

BMI, Body mass index; FPL, federal poverty level; PHQ-2, Public Health Questionnaire-2.
Among all participants, 69\% reported no food insecurity within the past 30 days; $24 \%$ reported food insecurity on some days; $4 \%$ reported food insecurity on most days; and 3\% reported food insecurity during all of the past 30 days. The proportion of respondents reporting "some" and "most or all" days of food insecurity across communities was as follows: $\mathrm{AI} / \mathrm{AN}(32 \%$ and $12 \%$, respectively), Hispanic (32\% and $10 \%$, respectively), African Immigrant/Refugee (30\% and $1 \%$, respectively), Pacific Islander (25\% and $8 \%$, respectively), African American (14\% and 5\%, respectively), and rural Non-Hispanic white (6\% and $0 \%$, respectively). Reported levels of food insecurity (19\%-43\%) among the communities of color were higher than both the state $(12 \%)$ and the national average $(13 \%){ }^{2}$

When examining dietary and physical activity behaviors associated with food insecurity (Table 2), average consumption of fruit and vegetables per day

Table 2. Association Between Self-Reported Food Insecurity in the Past 30 Days and Dietary and Physical Activity Characteristics

\begin{tabular}{|c|c|c|c|c|}
\hline & $\begin{array}{l}\text { No food } \\
\text { insecurity } \\
\text { reported } \\
\text { in past } \\
30 \text { days } \\
(n=355)\end{array}$ & $\begin{array}{c}\text { Food } \\
\text { insecurity } \\
\text { reported } \\
\text { in some of } \\
\text { the past } \\
30 \text { days } \\
(n=126)\end{array}$ & $\begin{array}{c}\text { Food } \\
\text { insecurity } \\
\text { reported } \\
\text { in most } \\
\text { or all of } \\
\text { the past } \\
30 \text { days } \\
(n=35)\end{array}$ & $p$ \\
\hline $\begin{array}{l}\text { Consumption of } 5+ \\
\text { fruits and vegetables } \\
\text { per day, } n(\%)\end{array}$ & $100(28.2)$ & $38(30.2)$ & $9(25.7)$ & 0.85 \\
\hline $\begin{array}{c}\text { Meets physical activity } \\
\text { guidelines }{ }^{\mathrm{a}}, n(\%)\end{array}$ & $127(35.8)$ & $34(27.0)$ & $12(34.3)$ & 0.20 \\
\hline $\begin{array}{l}\text { Weekly mean (SD) } \\
\text { other vegetable } \\
\text { intake }\end{array}$ & $5.0(6.4)$ & $3.8(5.5)$ & $2.9(3.1)$ & $<0.05$ \\
\hline $\begin{array}{l}\text { Weekly mean (SD) } \\
\text { orange vegetable } \\
\text { intake }\end{array}$ & $2.7(5.1)$ & $2.0(3.4)$ & $3.5(6.9)$ & 0.19 \\
\hline $\begin{array}{l}\text { Weekly mean (SD) } \\
\text { green vegetable } \\
\text { intake }\end{array}$ & $5.0(8.1)$ & $4.3(5.5)$ & $2.3(2.6)$ & $<0.05$ \\
\hline $\begin{array}{l}\text { Weekly mean (SD) } \\
\text { bean intake }\end{array}$ & $2.0(3.9)$ & $2.6(4.2)$ & $1.3(1.5)$ & $<0.05$ \\
\hline $\begin{array}{l}\text { Weekly mean (SD) } \\
\text { water intake }\end{array}$ & $36.7(23.2)$ & 36.1 (21.5) & $39.5(28.4)$ & 0.80 \\
\hline $\begin{array}{l}\text { Weekly mean (SD) juice } \\
\text { intake }\end{array}$ & $3.1(6.4)$ & $3.3(8.7)$ & $4.7(10.4)$ & 0.67 \\
\hline $\begin{array}{l}\text { Weekly mean (SD) fruit } \\
\text { intake }\end{array}$ & $11.9(9.4)$ & $12.4(11.7)$ & $9.9(13.5)$ & 0.44 \\
\hline $\begin{array}{l}\text { Weekly mean (SD) fast } \\
\text { food intake }\end{array}$ & $2.0(4.5)$ & $1.7(4.5)$ & $2.3(5.9)$ & 0.67 \\
\hline $\begin{array}{l}\text { Weekly mean (SD) soda } \\
\text { intake }\end{array}$ & $4.5(8.5)$ & $4.9(6.8)$ & $5.9(9.6)$ & 0.64 \\
\hline
\end{tabular}

${ }^{\text {a }}$ Meets CDC guidelines defined as $\geq 2.5$ hours per week of moderate to vigorous physical activity.

$\mathrm{SD}$, standard deviation. 
and participation in at least 2.5 hours per week of moderate-to-vigorous physical activity did not differ between those with and without food insecurity.

When stratified by individual components of diet, weekly consumption of orange vegetables, fruit, $100 \%$ fruit juice, or water did not substantially differ by food security status. Weekly consumption of "other" vegetables (including tomato, corn, eggplant, peas, lettuce, cabbage, and white potatoes), green vegetables, and beans significantly differed between food security groups. Food secure individuals consumed an average of 5.0 (SD: 6.4) "other" vegetables per week, individuals with some food insecurity in the past 30 days consumed 3.8 (SD: 5.5) "other" vegetables per week, and individuals with food insecurity in most or all of the past 30 days consumed "other" vegetables 2.9 (SD: $3.1)$ times per week $(p<0.05)$. Those without food insecurity consumed dark green vegetables at higher levels that those with food insecurity (5.0 vs. 4.3 [some] vs. 2.3 [most or all], respectively, $p<0.05$ ).

In unadjusted analyses (Table 3 ), food insecurity risk was associated with all health measures (including obesity, a positive depression score, and poor or fair self-rated health), being an urban woman of color compared with a non-Hispanic rural white, the presence of children in the home, low income, and residence in a food desert.

In the fully adjusted multivariate model, individuals who were obese had an increased odds of reporting food insecurity compared with individuals of normal weight or overweight (OR: 1.71, 95\% CI: 1.08-2.71), although results were not statistically significant when applying the Bonferroni correction. Individuals with a positive PHQ-2 depression score had 2.12 (95\% CI: 1.29-3.50) times the odds of reporting food insecurity compared with those with a negative PHQ-2 depression score.

Other factors associated with food insecurity in the fully adjusted model included being an urban woman of color, with all groups having an increased risk of food insecurity compared with rural non-Hispanic whites as well as FPL. A dose-response relation was observed among individuals with lower income having a higher odds of food insecurity compared with individuals with higher income levels. Although no statistically significant association was observed, those with fair or poor self-rated health had slightly increased odds of reporting food insecurity compared with those with excellent, very good, or good self-rated health (OR: 1.35, 95\% CI: 0.87-2.10).

\section{Discussion}

In this cross-sectional study investigating food insecurity among a group of diverse women of color and rural non-Hispanic whites, we found associations between both obesity and food insecurity as well as between depression and increased odds of experiencing food insecurity. These associations are congruent with findings from other studies. ${ }^{6-9}$ Food insecurity among women is important, as female study respondents are generally more likely to report household food insecurity when compared with male respondents. ${ }^{28}$ A 2017 metaanalysis found that female-headed households were $75 \%$ more likely to be food insecure than male-headed households (95\% CI 49-96). ${ }^{28}$

Although the relationship between poverty and food insecurity among women has been well established, ${ }^{29-32}$ food insecurity specifically among women of color, holding income constant, is emerging in the literature. Women from Pacific Islander, AI/AN, and refugee communities are currently underrepresented in the literature. Our findings add to this literature by highlighting a broader range of racial/ethnic communities.

Many of the communities in this study have not been traditionally included in research, highlighting that these groups may have unique risk profiles. These differences suggest that there might be a need for culturally tailored nutrition education programming focused on reducing food insecurity for these high-risk groups. ${ }^{33}$

It may be instructive to identify how race/ethnicity and food insecurity interact to increase the risk of poor health outcomes in such groups. Unfortunately, sample sizes for these groups do not allow for exploration of such interactions in the current study, indicating a need for future research with these populations.

In addition, our small sample size precludes us from making conclusions about differences in food insecurity between any groups other than indicating a statistically significant difference in food insecurity among rural whites and other racial/ethnic groups included in our study. Future work should include qualitative methods such as personal interviews and focus groups with members of different communities to gain a better understanding of barriers and facilitators to decreasing food insecurity, particularly in under-studied communities.

The association between food insecurity and obesity has been demonstrated in previous studies. ${ }^{6,34-39}$ Three studies that focused on communities of color found an association between food insecurity, poor diet, and obesity ${ }^{35,36,40}$ whereas only one found no association. ${ }^{39}$ 
Table 3. Multivariable Logistic Regression Results for Self-Reported Food Insecurity During Some, Most, or All of the Past 30 Days Versus No Food Insecurity in the Past 30 Days $(N=516)$

\begin{tabular}{|c|c|c|c|c|c|c|}
\hline \multirow[b]{2}{*}{ Characteristic } & \multicolumn{2}{|c|}{ Unadjusted } & \multicolumn{2}{|c|}{ Adjusted Model A } & \multicolumn{2}{|c|}{ Adjusted Model B } \\
\hline & OR & $95 \% \mathrm{Cl}$ & OR & $95 \% \mathrm{Cl}$ & OR & $95 \% \mathrm{Cl}$ \\
\hline \multicolumn{7}{|l|}{ BMI } \\
\hline Normal weight/overweight & 1.00 & Reference & 1.00 & Reference & 1.00 & Reference \\
\hline Obese & 1.54 & $1.04-2.29$ & 1.38 & $0.91-2.09$ & 1.71 & $1.08-2.71$ \\
\hline \multicolumn{7}{|l|}{ PHQ-2 depression score } \\
\hline Negative & 1.00 & Reference & 1.00 & Reference & 1.00 & Reference \\
\hline Positive & 2.26 & $1.46-3.49$ & 1.93 & $1.23-3.04^{*}$ & 2.12 & $1.29-3.50^{*}$ \\
\hline \multicolumn{7}{|l|}{ Self-rated health } \\
\hline Excellent, very good, good & 1.00 & Reference & 1.00 & Reference & 1.00 & Reference \\
\hline Fair, poor & 2.09 & $1.43-3.06$ & 1.72 & $1.15-1.26^{*}$ & 1.35 & $0.87-2.10$ \\
\hline \multicolumn{7}{|l|}{ Community } \\
\hline Rural non-Hispanic white & 1.00 & Reference & NA & & 1.00 & Reference \\
\hline Urban American Indian/Alaskan Native & 11.97 & $3.41-42.02$ & & & 8.84 & $2.37-33.02$ \\
\hline Urban Hispanic & 10.95 & $3.24-37.02$ & & & 7.38 & $2.02-26.89$ \\
\hline Urban Native Hawaiian/Pacific Islander & 7.53 & $2.15-26.35$ & & & 8.38 & $2.20-31.94$ \\
\hline Urban African Immigrant/Refugee & 7.07 & $2.00-25.05$ & & & 4.35 & $1.11-16.70$ \\
\hline Urban African American & 3.55 & $1.00-12.65$ & & & 4.70 & $1.26-17.58$ \\
\hline \multicolumn{7}{|l|}{ Children in home } \\
\hline No & 1.00 & Reference & NA & & 1.00 & Reference \\
\hline Yes & 1.72 & $1.14-2.59$ & & & 1.04 & $0.61-1.77$ \\
\hline \multicolumn{7}{|l|}{$\mathrm{FPL}, \%$ of $\mathrm{FPL}$} \\
\hline$<100 \%$ & 5.55 & $2.98-10.31$ & & & 5.15 & $2.46-10.68$ \\
\hline $101 \%-130 \%$ & 4.01 & $1.89-8.52$ & & & 3.54 & $1.55-8.07$ \\
\hline $131 \%-185 \%$ & 3.08 & $1.47-6.45$ & & & 2.71 & $1.23-5.96$ \\
\hline$>185 \%$ & 1.00 & Reference & NA & & 1.00 & Reference \\
\hline Not reported & 2.68 & $1.08-6.67$ & & & 3.31 & $1.22-8.97$ \\
\hline \multicolumn{7}{|l|}{ Food desert } \\
\hline No & 1.00 & Reference & NA & & 1.00 & Reference \\
\hline Yes & 1.65 & $1.06-2.55$ & & & 1.51 & $0.93-2.47$ \\
\hline \multicolumn{7}{|l|}{ Age, years } \\
\hline $18-29$ & 1.00 & Reference & NA & & 1.00 & Reference \\
\hline $30-39$ & 1.36 & $0.81-2.31$ & & & 1.24 & $0.69-2.25$ \\
\hline $40-49$ & 1.40 & $0.81-2.41$ & & & 1.35 & $0.71-2.56$ \\
\hline$\geq 50$ & 0.77 & $0.44-1.33$ & & & 0.97 & $0.50-1.90$ \\
\hline \multicolumn{7}{|l|}{ Education } \\
\hline Less than high school & 1.00 & Reference & NA & & 1.00 & Reference \\
\hline High school graduate & 1.08 & $0.56-2.09$ & & & 1.69 & $0.81-3.55$ \\
\hline Some college & 0.90 & $0.48-1.69$ & & & 1.70 & $0.82-3.51$ \\
\hline$\geq$ College & 0.56 & $0.28-1.12$ & & & 1.50 & $0.67-3.33$ \\
\hline \multicolumn{7}{|l|}{$5+$ Fruit and vegetable servings per day } \\
\hline No & 1.00 & Reference & NA & & 1.00 & Reference \\
\hline Yes & 1.05 & $0.70-1.59$ & & & 1.17 & $0.73-1.86$ \\
\hline \multicolumn{7}{|l|}{$2.5+$ Hours of weekly exercise } \\
\hline No & 1.00 & Reference & NA & & 1.00 & Reference \\
\hline Yes & 0.72 & $0.48-1.08$ & & & 0.88 & $0.55-1.40$ \\
\hline
\end{tabular}

*Statistically significant with Bonferroni correction applied.

It has been hypothesized that the mechanism behind this finding is that either the consumption of low-cost, calorie-dense, nutrient-deprived food by those with food insecurity leads to obesity or fattening is a physiological response to a threatened food supply. ${ }^{6}$

Although we saw an association between obesity and food insecurity and found no appreciable association between food insecurity and self-reported intake of five or more servings of fruit and vegetables per day, frequency of fast food consumption, frequency of soda consumption, or intake of some specific types of fruits and vegetables, we did observe a difference between intake of green vegetables, beans, and other vegetables.

It should also be noted that although our data indicate that individuals with and without food insecurity are eating similar quantities of most fruits and vegetables, we 
were unable to evaluate the quality and source of these foods, such as fresh versus canned or frozen fruits and vegetables.

Our finding of a positive association between food insecurity and depression has been corroborated by other studies. ${ }^{7-9,41,42}$ One prior study observed that depression and anxiety are more common among food insecure individuals, particularly among women. ${ }^{8} \mathrm{~A}$ study that examined depression among Supplemental Nutrition Assistance Program (SNAP) participants found that very low food security was associated with higher odds of depression in both participants and eligible nonparticipants. ${ }^{42}$ Although we are unable to determine the direction of this association in this analysis, it is likely that the relationship is bidirectional: Food security may affect mental health as a stressor ${ }^{41}$ and depression may have negative impacts on a woman's ability to work, and/or obtain and prepare food, thus contributing to food insecurity. ${ }^{43,44}$

As of 2016, 12\% of Utah residents reported being food insecure, which is near the national average of $13 \%{ }^{2,45}$ Our findings indicate that even in a state with average levels of food insecurity, striking disparities may be present in subgroups as the rate of food insecurity in our sample was $30 \%$.

A strength of our work is the inclusion of urban women of color from multiple communities and the inclusion of non-Hispanic white rural women. We were also able to differentiate between African immigrants and refugees compared with African Americans, distinct groups that are traditionally analyzed as a single group. ${ }^{44}$ In addition, the utilization of wellness coaches for participant recruitment enabled us to reach diverse and historically underserved study participants. That said, we also acknowledge that the sample in the current study is not likely fully representative of these groups due to convenience sampling methods and the geographic restrictions of the study.

Limitations of our study include lack of an urban, non-Hispanic white comparison group and relying on self-reported information for dietary composition. The lack of an urban non-Hispanic white comparison group limits the ability to compare the odds of food insecurity for these community groups with the dominant racial/ethnic group in the area. The reference group utilized was rural non-Hispanic whites, who have a higher incidence of food insecurity than urban non-Hispanic whites; thus, the odds observed in this study are likely an underestimate of the odds compared with urban non-Hispanic whites.
Self-reported data might be subject to social desirability reporting or error in recall, particularly for foods that are eaten rarely. There is a possibility that the study results may be affected by dependent misclassification as food insecurity and health outcomes, specifically self-reported health and depression, were assessed at the same time point and using the same instrument, a self-report questionnaire. ${ }^{46}$

In addition, this study assessed food insecurity status based on a single question that restricted the report of food insecurity to the past 30 days. Recent work is utilizing more detailed instruments that may provide a more accurate ascertainment of food insecurity. The question utilized in this study, however, was adapted from a BRFSS question that had been previously used in Utah and allows for comparison to local and national data. ${ }^{47}$ In addition, to achieve sufficient statistical power in the multivariable analyses we combined all levels of food insecurity (all, most, and some days) for the past 30 days, which limited our ability to observe the association between health and more detailed levels of food insecurity.

Our findings are potentially impacted by residual confounding, as we did not have information about types of food supports that some study participants may have had access to, including SNAP benefits, food banks, or other religious or community food assistance programs.

Lastly, because of the cross-sectional nature of our data, we are unable to determine causality or temporality. The relationship between food insecurity and health are likely bi-directional and complex. Although our study design allowed us to evaluate the differences in food security and the disproportionality of the studied health conditions among women of color, future longitudinal studies are recommended.

The role of food assistance programs in mitigating food insecurity among our sample was not investigated, as gathering data on program participation was not part of the original study design. However, we know that among all SNAP participants, slightly less than one-quarter remain food insecure. ${ }^{48}$ Moreover, research has found that reports of food insecurity among SNAP recipients increase, and that healthy eating awareness declines, with the number of days that have elapsed since a household's receipt of its monthly SNAP benefit. ${ }^{49,50}$

Qualitative research also reveals that SNAP recipients' coping strategies toward the end of the month often include skipping meals and seeking instrumental 
food supports from family and friends. ${ }^{51}$ These findings coupled with the relatively high rates of food insecurity observed in our targeted community samples and differences in the intake of some food types suggest that an investigation of the potential interplay between community group membership and the structure of food assistance programs could be an important policy-relevant area for future research.

Screening for social determinants of health is becoming more common in clinical settings, and, as such, screening for food insecurity is increasing. With the implementation of screening, clinicians will undoubtedly encounter patients with food insecurity and other key social determinants such as poverty, violence, unemployment, and unstable housing. ${ }^{52}$ Our findings suggest that these routine screening for social determinants of health should include food insecurity questions. The health care system can play an important role in helping link patients with social services to address their unique social determinant needs.

\section{Conclusions}

In this study of five distinct groups of women of color and rural non-Hispanic whites in Utah, we found that self-reported food insecurity was associated with depression, obesity, income, and racial/cultural group membership in multivariable models. This study was one of the first to target under-represented racial/ ethnic groups such as African refugees/immigrants and Pacific Islanders.

Our findings indicate a need to investigate why certain health factors and racial/cultural group membership are linked to relatively high risks of food insecurity. Our findings of persistent differences in food insecurity by ethnic group suggest that culturally targeted efforts, elucidating availability and utilization of food assistance programs, and screenings in clinical settings may be needed to address food insecurity in these high-risk groups.

\section{Acknowledgments}

The authors would like to acknowledge all of the coaches who collected data for this study and the public health students who have assisted in the project. The authors would also like to acknowledge the contributions from the CHC-UWAG. Members include: Utah Women's Health Coalition: Community Faces of Utah; Best of Africa: Valentine Mukundente; Calvary Baptist Church: Pastor France A. Davis, Doriena Lee; Hispanic Health Care Task Force: Sylvia Rickard (de- ceased), Ana Sanchez-Birkhead, Jeannette Villalta; National Tongan American Society: O. Fahina TavakePasi, Ivoni Nash; Urban Indian Center: Eru Napia; Utah Department of Health: Brenda Ralls; University of Utah and Utah Center for Clinical \&Translational Science: Stephen C. Alder, Louisa A. Stark, Heather Coulter; University of Utah: Grant Sunada; University of Utah Center of Excellence in Women's Health: Leanne Johnston; University of Utah, College of Health: Patricia Eisenman; University of Utah Department of Biomedical Informatics: Bernie LaSalle; Utah State University Cooperative Extension Service: Duchesne County: Suzanne Prevedel; and Wayne County: Gaelynn Peterson; San Juan County: Lou Mueller; Beaver County: Cindy Nelson.

\section{Authors' Contributions}

S.K.W., S.E.S. had full access to all of the data in the study and take responsibility for the integrity of the data and the accuracy of the data analysis. R.B.H. had full access to the geographic data in the study and take responsibility for the integrity of the geographic data and the accuracy of the geographic data analysis. S.E.S. supervised the study. S.E.S., C.D.Z., and K.B.D, were involved in the study concept and design. S.E.S. was responsible for acquisition of data. S.K.W. and R.B.H. did the analysis and interpretation of data. S.K.W., S.E.S., R.B.H., J.B., C.D.Z., and K.B.D. drafted the article and critically revised the article for important intellectual content.

\section{Ethical Standards}

This study was conducted according to the guidelines laid down in the Declaration of Helsinki, and all procedures involving human subjects/patients were approved by the University of Utah Institutional Review Board and the Phoenix Area Indian Health Service Institutional Review Board. Verbal informed consent was obtained from all subjects/patients.

\section{Author Disclosure Statement}

The authors declare that they have no conflicts of interest.

\section{Funding Information}

This research was supported by the Office on Women's Health, Department of Health and Human Services [Grant 1CCEWH111018-01-00]; University of Utah, Center of Excellence in Women's Health and Center for Clinical and Translational Science; and National 
Institutes of Health, National Center for Advancing Translational Sciences [Grant (8UL1TR000105 (formerly UL1RR025764) NCATS/NIH)]. This study is registered under the Coalition for a Healthier Community-Utah Women and Girls-Phase II (UWAGII). The study is registered at https://clinicaltrials.gov/ct2/show/ NCT02470156 (No. NCT02470156).

\section{References}

1. United States Department of Agriculture. Documentation. 2017. Available at: https://www.ers.usda.gov/data-products/food-security-in-the-unitedstates/documentation Accessed June 15, 2020.

2. Coleman-Jensen A, Rabbitt M, Gregory C, Singh A. Household food security in the United States in 2015. Washington, DC: USDA ERS, 2016.

3. Seligman HK, Laraia BA, Kushel MB. Food insecurity is associated with chronic disease among low-income NHANES participants. J Nutr 2010 140:304-310.

4. Ivers LC, Cullen KA. Food insecurity: Special considerations for women. Am J Clin Nutr 2011;94:1740S-1744S.

5. McCall L. The complexity of intersectionality. Signs 2005;30:1771-1800.

6. Dinour LM, Bergen D, Yeh MC. The food insecurity-obesity paradox: A review of the literature and the role food stamps may play. J Am Diet Assoc 2007;107:1952-1961.

7. Siefert K, Heflin CM, Corcoran ME, Williams DR. Food insufficiency and the physical and mental health of low-income women. Women Health 2001 ; 32:159-177.

8. Huddleston-Casas C, Charnigo R, Simmons LA. Food insecurity and maternal depression in rural, low-income families: A longitudinal investigation. Public Health Nutr 2009;12:1133-1140.

9. Siefert K, Heflin CM, Corcoran ME, Williams DR. Food insufficiency and physical and mental health in a longitudinal survey of welfare recipients. J Health Soc Behav 2004;45:171-186.

10. Gucciardi E, Vahabi M, Norris N, Del Monte JP, Farnum C. The intersection between food insecurity and diabetes: A review. Curr Nutr Rep 2014;3: 324-332.

11. Lyles $C R$, Wolf $M S$, Schillinger $D$, et al. Food insecurity in relation to changes in hemoglobin A1c, self-efficacy, and fruit/vegetable intake during a diabetes educational intervention. Diabetes Care 2013;36:14481453.

12. Ding M, Keiley MK, Garza KB, Duffy PA, Zizza CA. Food insecurity is associated with poor sleep outcomes among US adults. J Nutr 2015;145: 615-621.

13. Goldberg SL, Mawn BE. Predictors of food insecurity among older adults in the United States. Public Health Nurs 2015;32:397-407.

14. Bartfeld J, Dunifon R. State-level predictors of food insecurity among households with children. Policy Analysis and Management 2006;25: 921-942.

15. Buder I, Zick C, Waitzman N, Simonsen S, Sunada G, Digre K. It takes village coach: Cost-effectiveness of an intervention to improve diet and physical activity among minority women. J Phys Act Health 2018;15: 819-826.

16. Simonsen SE, Ralls B, Guymon A, et al. Addressing health disparities from within the community: Community-based participatory research and community health worker policy initiatives using a gender-based approach. Womens Health Issues 2017;27 Suppl 1:S46-S53.

17. Simonsen $S E$, Digre KB, Ralls $B$, et al. A gender-based approach to developing a healthy lifestyle and healthy weight intervention for diverse Utah women. Eval Program Plann 2015;51:8-16.

18. United States Census Bureau. Salt Lake County, Utah. State \& County QuickFacts. Washington, DC: United States Census Bureau, 2010.

19. QuickFacts. United States Cenus Bureau, 2010.

20. Irving SM, Njai RS, Siegel PZ. Food insecurity and self-reported hypertension among Hispanic, black, and white adults in 12 states, Behavioral Risk Factor Surveillance System, 2009. Prev Chronic Dis 2014; 11:E161.

21. Behavioral Risk Factor Surveillance System Questionnaire. Atlanta, GA: Centers for Disease Control Prevention, 2013.
22. World Health Organization. Regional Office for the Western Pacific. The Asia-Pacific perspective: Redefining obesity and its treatment. International Diabetes Institute, International Association for the Study of Obesity International Obesity Task Force. Sydney: Health Communications Australia, 2000.

23. Hsu WC, Boyko EJ, Fujimoto WY, et al. Pathophysiologic differences among Asians, native Hawaiians, and other Pacific Islanders and treatment implications. Diabetes Care 2012;35:1189-1198.

24. Swinburn BA, Ley SJ, Carmichael HE, Plank LD. Body size and composition in Polynesians. Int J Obes Relat Metab Disord 1999;23: 1178-1183.

25. Current Physical Activity Guidelines. Centers for Disease Control and Prevention, Atlanta, GA, 2016.

26. Economic Research Service. Food Access Research Atlas. Washington, DC: United States Department of Agriculture, 2017.

27. Economic Research Service. Food Prices and Spending. Washington, DC: United States Department of Agriculture 2017.

28. Jung NM, de Bairros FS, Pattussi MP, Pauli S, Neutzling MB. Gender differences in the prevalence of household food insecurity: A systematic review and meta-analysis. Public Health Nutr 2017 20:902-916

29. Rose D, Gundersen C, Oliveira V. Socio-Economic Determinants of Food Insecurity in the United States: Evidence from the SIPP and CSFII Datasets. Technical Bulletin 1869 Economic Research Service, US Department of Agriculture, Washington, DC, 1998.

30. Rose D. Economic determinants and dietary consequences of food insecurity in the United States. J Nutr 1999;129:517S-520S.

31. Hamilton W, Cook JT, Thompson WW, et al. Household food security in the United States in 1995: Summary Report of the Food Security Measurement Project. Washington, DC: FCS/USDA, 1997.

32. Alaimo K, Briefel RR, Frongillo EA, Olson CM. Food insufficiency exists in the United States: Results from the third National Health and Nutrition Examination Survey (NHANES III). Am J Public Health 1998;88: 419-426.

33. Eicher-Miller HA, Mason AC, Abbott AR, McCabe GP, Boushey CJ. The effect of Food Stamp Nutrition Education on the food insecurity of lowincome women participants. J Nutr Educ Behav 2009;41:161-168.

34. Bauer KW, Widome $\mathrm{R}$, Himes $\mathrm{JH}$, et al. High food insecurity and its correlates among families living on a rural American Indian Reservation. Am J Public Health 2012;102:1346-1352.

35. Dharod JM, Croom JE, Sady CG. Food insecurity: Its relationship to dietary intake and body weight among Somali refugee women in the United States. J Nutr Educ Behav 2013;45:47-53.

36. Vedovato GM, Surkan PJ, Jones-Smith J, et al. Food insecurity, overweight and obesity among low-income African-American families in Baltimore City: Associations with food-related perceptions. Public Health Nutr 2016; 19:1405-1416.

37. Dhurandhar EJ. The food-insecurity obesity paradox: A resource scarcity hypothesis. Physiol Behav 2016;162:88-92.

38. Franklin B, Jones A, Love D, Puckett S, Macklin J, White-Means S. Exploring mediators of food insecurity and obesity: A review of recent literature. J Community Health 2012;37:253-264.

39. Robaina KA, Martin KS. Food insecurity, poor diet quality, and obesity among food pantry participants in Hartford, CT. J Nutr Educ Behav 2013; 45:159-164.

40. Mello JA, Gans KM, Risica PM, Kirtania U, Strolla LO, Fournier L. How is food insecurity associated with dietary behaviors? An analysis with lowincome, ethnically diverse participants in a nutrition intervention study. J Am Diet Assoc 2010;110:1906-1911.

41. Heflin CM, Siefert K, Williams DR. Food insufficiency and women's menta health: Findings from a 3-year panel of welfare recipients. Soc Sci Med 2005;61:1971-1982

42. Leung CW, Epel ES, Willett WC, Rimm EB, Laraia BA. Household food insecurity is positively associated with depression among low-income supplemental nutrition assistance program participants and incomeeligible nonparticipants. J Nutr 2015;145:622-627.

43. Rizvi SJ, Cyriac A, Grima E, et al. Depression and employment status in primary and tertiary care settings. Can J Psychiatry 2015;60:14-22.

44. Arthur CM, Katkin ES. Making a case for the examination of ethnicity of Blacks in United States Health Research. J Health Care Poor Underserved 2006;17:25-36. 
45. Mendy VL, Vargas R, Cannon-Smith G, Payton M, Enkhmaa B, Zhang L. Food insecurity and cardiovascular disease risk factors among Mississippi adults. Int J Environ Res Public Health 2018;15.

46. Lash TL, Fink AK. Re: "Neighborhood environment and loss of physical function in older adults: Evidence from the Alameda County Study". Am J Epidemiol 2003;157:472-473.

47. Centers for Disease Control and Prevention. Self-reported concern about food security associated with obesity-Washington, 1995-1999. MMWR Morb Mortal Wkly Rep 2003;52:840-842.

48. Schanzenbach DW, Bauer L, Nantz G. Twelve facts about food insecurity and SNAP. Washington DC: Brookings Institution, 2016.

49. Dorfman JH, Gregory C, Liu Z, Huo R. Re-examining the SNAP benefit cycle allowing for heterogeneity. Appl Econ Perspect Policy 2019;41. 404-433.

50. He X. Agriculture, food, and health: Changes in industry structure and consumer behavior. Storrs, CT: University of Connecticut, 2019.

51. Kinsey EW, Oberle M, Dupuis R, Cannuscio CC, Hillier A. Food and financial coping strategies during the monthly Supplemental Nutrition Assistance Program cycle. SSM Popul Health 2019;7:100393.

52. Andermann A. Screening for social determinants of health in clinical care: Moving from the margins to the mainstream. Public Health Rev 2018;39:19.
Cite this article as: Willis SK, Simonsen SE, Hemmert RB, Baayd J, Digre KB, Zick CD (2020) Food insecurity and the risk of obesity, depression, and self-rated health in women, Women's Health Report 1:1, 308-317, DOI: 10.1089/whr.2020.0049

Abbreviations Used
$\mathrm{Al} / \mathrm{AN}=$ American Indian/Alaska Native
$\mathrm{BRFSS}=$ Behavioral Risk Factor Surveillance System
$\mathrm{Cl}=$ confidence interval
$\mathrm{FARA}=$ Food Access Research Atlas
$\mathrm{FPL}=$ federal poverty level
$\mathrm{GIS}=$ Geographic Information System
$\mathrm{PHQ}-2=$ Public Health Questionnaire-2
$\mathrm{SNAP}=$ Supplemental Nutrition Assistance Program
$\mathrm{UWAG}=$ Utah Women and Girls

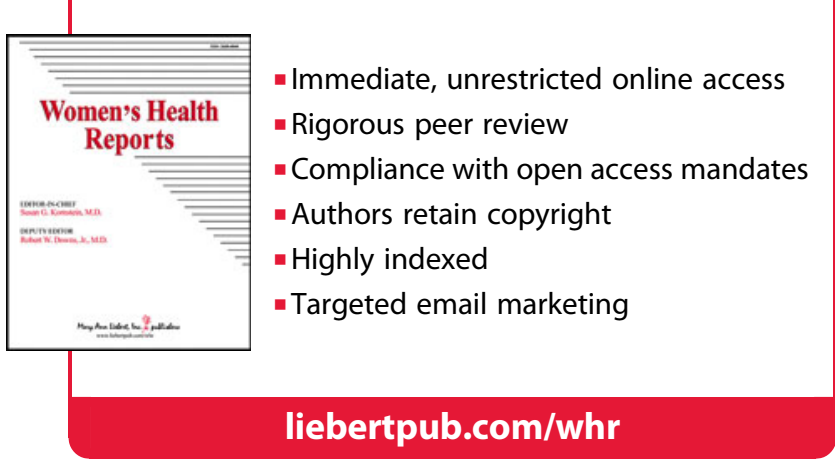

